\title{
PROMKES PERILAKU CERDIK UNTUK PENCEGAHAN KANKER PADA KELOMPOK GURU BINA AMAL SEMARANG
}

\author{
Dyah Restuning Prihati ${ }^{1}$, Maulidta Karunianingtyas Wirawati ${ }^{2}$, Endang Supriyanti ${ }^{3}$ \\ 1,2,3 Universitas Widya Husada Semarang \\ Email: dyah.erpe@gmail.com
}

\begin{abstract}
ABSTRAK
Penyebab kematian utama salah satunya adalah penyakit kanker. Kanker menempati sepuluh besar penyakit penyebab kematian di Indonesia. Permasalahan mitra diantaranya pengetahuan guru tentang kanker, bahaya dan cara pencegahan kurang; belum ada penyuluhan tentang kanker oleh petugas kesehatan. Tujuan Promosi kesehatan perilaku CERDIK untuk meningkatkan pengetahuan guru tentang kanker, bahaya dan cara pencegahan; meningkatkan kesadaran dan kewaspadaan terhadap bahaya penyakit kanker; meningkatkan perilaku hidup sehat untuk mencegah penyakit kanker dengan perilaku CERDIK. Sasaran kegiatan ini adalah kelompok guru Bina Amal Semarang. Metode yang akan digunakan adalah Promosi kesehatan meliputi penyuluhan tentang kewaspadaan dini terhadap penyakit kanker, pemutaran video tentang SADARI dan pelatihan pengukuran tekanan darah kepada guru dan pendampingan. Hasil Kegiatan ini terdapat peningkatan pengetahuan kelompok guru setelah diberikan promosi kesehatan tentang pencegahan dini kanker. Salah satu upaya untuk meningkatkan pengetahuan masyarakat tentang penyakit kanker dan upaya deteksi dini pencegahan kanker dengan melakukan kegiatan promotif dan preventif. Diharapkan dengan implementasi perilaku CERDIK bisa diterapkan di sekolah dengan bimbingan yang diberikan oleh para guru kepada siswanya dan wali orangtua siswa.
\end{abstract}

Kata Kunci : Kelompok Guru, Promkes, Cegah Kanker.

\begin{abstract}
One of the main causes of death is cancer. Cancer occupies the top ten diseases that cause death in Indonesia. Partner problems include teachers' lack of knowledge about cancer, dangers and prevention methods; there has been no education about cancer by health workers. The objective of CERDIK Behavioral Health Promotion to increase teachers' knowledge about cancer, its dangers and prevention methods; raise awareness and awareness of the dangers of cancer; promote healthy living habits to prevent cancer with ENDICHING behavior. The target of this activity is the Bina Amal Semarang teacher group. The method that will be used is health promotion which includes counseling on early awareness of cancer, video screening of BSE and training in measuring blood pressure for teachers and mentoring. The result of this activity was an increase in the knowledge of the teacher group after being given health promotion on early cancer prevention. One of the efforts to increase public knowledge about cancer and early detection of cancer
\end{abstract}


prevention is by carrying out promotional and preventive activities. It is hoped that the implementation of CERDIK behavior can be applied in schools with the guidance provided by teachers to students and parents of students.

Keywords: Teacher Group, Health Promotion, Prevent Cancer

\section{PENDAHULUAN}

Penyebab kematian utama salah satunya adalah penyakit kanker. Kanker menempati sepuluh besar penyakit penyebab kematian di Indonesia. Data Riset Kesehatan Dasar (Riskesdas) tahun 2013 menyatakan angka insiden kanker di Indonesia yaitu 1,4 per 1000 penduduk. Angka kejadian penyakit kanker di Yogyakarta sekitar 4,1\%, Jawa Tengah sekitar 2,1\%, Bali sekitar 2\%, Bengkulu dan DKI Jakarta sebanyak 1,9 per mil (Kemenkes, 2015). Gerakan Pencegahan dan Deteksi Dini Kanker pada Perempuan Indonesia meliputi kegiatan promotif, preventif, deteksi dini, dan tindak lanjut. Peningkatan kesadaran masyarakat dalam pencegahan risiko kanker dan deteksi dini kanker untuk menekan angka kesakitan, kematian akibat kanker (Kemenkes, 2015).

Tema hari kanker sedunia tahun 2018 ini merupakan bagian dari tema untuk rangkaian tiga tahun 2016-2018 yaitu "Kita Bisa. Aku Bisa" yang bertujuan menjangkau masyarakat untuk menjalankan perannya masingmasing dalam rangka mengurangi beban akibat kanker. Pencegahan kanker dengan perilaku CERDIK ( Cek kesehatan secara berkala, Enyahkan asap rokok, Rajin aktifitas fisik, Diet sehat dengan kalori seimbang, Istirahat cukup dan Kelola stres). Penyuluhan kesehatan merupakan salah satu media dalam pendidikan kesehatan untuk mempengaruhi perilaku kesehatan individu, kelompok atau masyarakat (Notoatmodjo, 2010). Hasil Penelitian menyatakan bahwa memberikan media leaflet dan video memiliki pengaruh yang besar terhadap peningkatan pengetahuan dan partisipasi wanita yang dapat menyimpan leaflet dan mudah mengingatnya melalui pemutaran video tentang kanker serviks (Ulfah A, 2017). Penelitian yang dilakukan oleh Yulinda (2018), media yang digunakan dalam penyuluhan kesehatan pada 100 orang remaja putri adalah media audiovisual berupa video. Video sebagai media audiovisual dalam proses penyampaian pesannya menggunakan indera penglihatan dan pendengaran.

Berdasarkan hal tersebut kegiatan promosi kesehatan perilaku CERDIK ini bertujuan untuk meningkatkan kewaspadaan dan pengetahuan mengenai penyakit kanker, serta menggerakkan masyarakat untuk melakukan upaya pencegahan, deteksi dini dan pengobatan terhadap penyakit kanker. 


\section{MASALAH}

Identifikasi permasalahan yang dihadapi mitra adalah belum ada penyuluhan tentang kanker oleh petugas kesehatan; pengetahuan guru tentang kanker, bahaya dan cara pencegahan kurang; belum ada penyuluhan tentang kanker oleh petugas kesehatan dan jarak Universitas Widya Husada dengan mitra dekat.

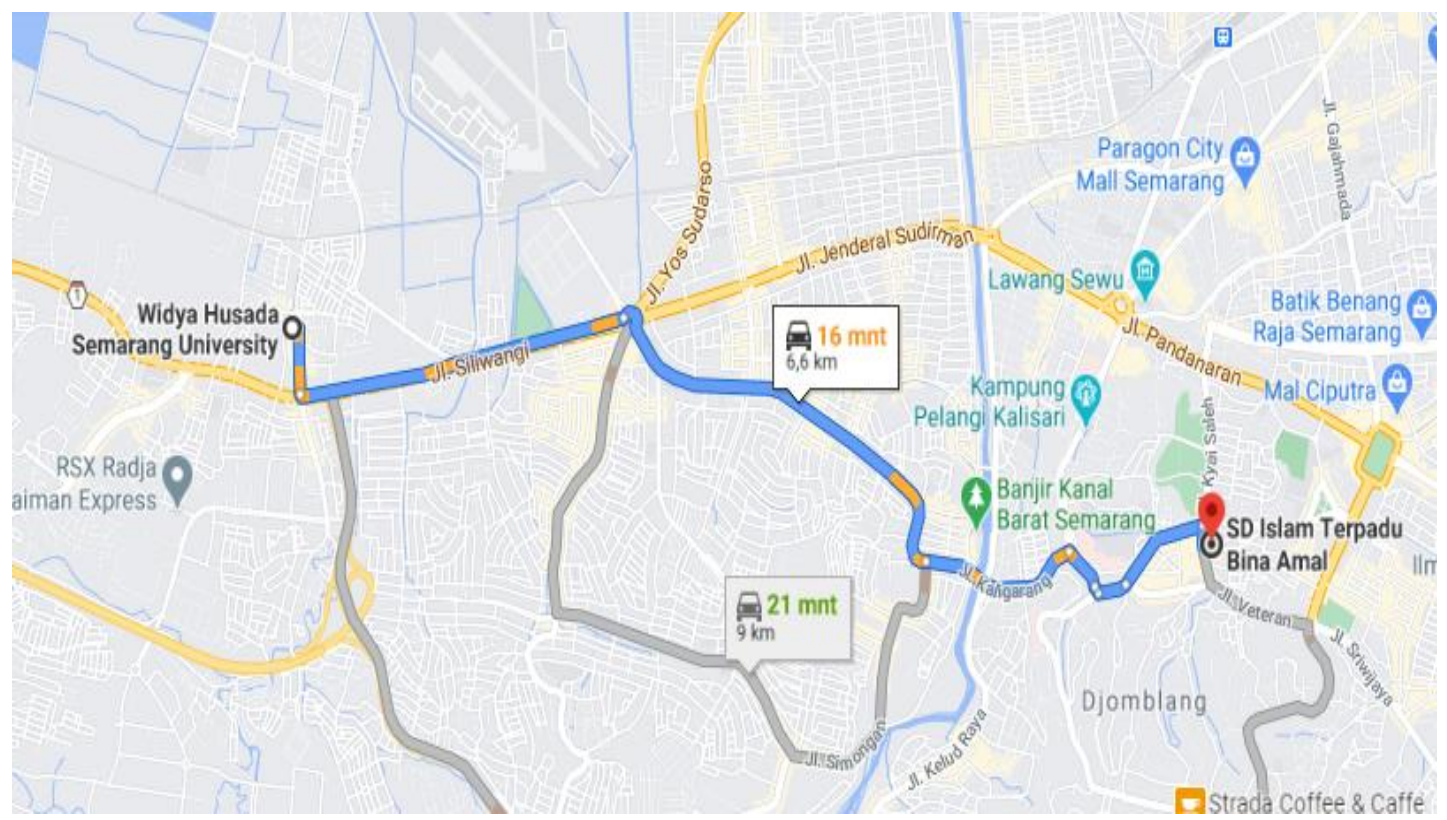

Gambar 2.1 Peta Lokasi Kegiatan Program Kemitraan Masyarakat.

\section{METODE}

a. Persiapan Kegiatan

Persiapan kegiatan dimulai dengan persiapan tempat dan media dipersiapkan sesuai dengan kebutuhan serta antisipasi kemungkinan masalah yang terjadi. Persiapan dilakukan untuk memulai kegiatan sehingga sesuai dengan sasaran dan tujuan yang diharapkan. Pembuatan booklet PROMKES Perilaku CERDIK Untuk Pencegahan Kanker.

b. Pelaksanaan Kegiatan

Promosi kesehatan dilaksanakan tanggal 27 September 2019 meliputi penyuluhan tentang kewaspadaan dini terhadap penyakit kanker, pemutaran video mengenai cara dan waktu untuk melakukan SADARI serta pelatihan pengukuran tekanan darah kepada guru dan pendampingan. Alokasi waktu promkes adalah 120 menit. Peserta yang hadir sebanyak 13 orang guru Bina Amal.

c. Evaluasi Kegiatan

Evaluasi kegiatan dilakukan dengan memberikan kuisioner pengetahuan dan redemonstrasi pengukuran tekanan darah pada kelompok guru yang mengikuti kegiatan. 


\section{HASIL DAN PEMBAHASAN}

Kegiatan Program Kemitraan Masyarakat meliputi :

a. Terselenggaranya promosi kesehatan dilaksanakan tanggal 27 September 2019 meliputi penyuluhan tentang kewaspadaan dini terhadap penyakit kanker dan pemutaran video mengenai cara dan waktu untuk melakukan SADARI. Tersedianya booklet promosi kesehatan tentang pencegahan dini kanker. booklet ini diharapkan akan menjadi bahan promkes untuk guru dan wali murid. Penyusunan modul disusun oleh tim pengusul. Setelah diberikan promosi kesehatan tentang pencegahan dini kanker, kelompok guru yang memiliki pengetahuan tinggi sebanyak 12 orang (92\%) dan yang memiliki pengetahuan rendah sebanyak 1 orang $(8 \%)$.

b. Pelatihan pengukuran tekanan darah kepada guru, sebagai upaya untuk melatih para guru agar mampu melakukan pemeriksaan tekanan darah. Setelah dilakukan pelatihan tekanan darah, seluruh peserta sebanyak 13 orang $(100 \%)$ terampil dalam melakukan pengukuran tekanan darah.

Pendidikan kesehatan berupa penyuluhan kesehatan merupakan salah satu media dalam pendidikan kesehatan untuk mempengaruhi perilaku kesehatan individu, kelompok atau suatu masyarakat (Notoatmodjo, 2010). Metode ceramah adalah metode yang dapat diterima dengan baik oleh sasaran yang memiliki pendidikan tinggi maupun rendah (Notoatmodjo, 2010). Metode ceramah dapat dilakukan dengan jumlah peserta yang cukup banyak (Mubarak, 2012). Media penyuluhan harus dapat diterima dengan baik oleh peserta penyuluhan salah satunya adalah alat bantu AVA (Audio Visual Aids). Machfoedz, dkk (2005) menyatakan bahwa AVA merupakan alat - alat pendidikan dalam bidang kesehatan merupakan alat saluran yang dapat digunakan untuk menyampaikan kesehatan karena alat alat tersebut digunakan untuk mempermudah penerimaan pesan - pesan kesehatan bagi audiens. Penelitian yang dilakukan oleh Lubis (2017) menyatakan bahwa memberikan media leaflet dan video memiliki pengaruh yang besar terhadap peningkatan pengetahuan dan partisipasi wanita yang dapat menyimpan leaflet dan mudah mengingatnya melalui pemutaran video tentang kanker serviks. Penelitian yang dilakukan oleh Yulinda (2018), media yang digunakan dalam penyuluhan kesehatan dengan media audiovisual berupa video. Metode ceramah dengan media audiovisual berupa video dalam penyuluhan kesehatan dapat meningkatkan pengetahuan dan sikap pada remaja putri. Video sebagai media audiovisual dalam proses penyampaian pesannya menggunakan indera penglihatan dan pendengaran (Arif, Yulinda, \& Fitriyah, 2018). Penginderaan manusia akan menghasilkan pengetahuan, karena pengetahuan merupakan hasil pikir dari seseorang terhadap suatu objek melalui indera yang dimilikinya seperti mata, telinga, hidung dan lainnya (Notoatmodjo, 2012). 

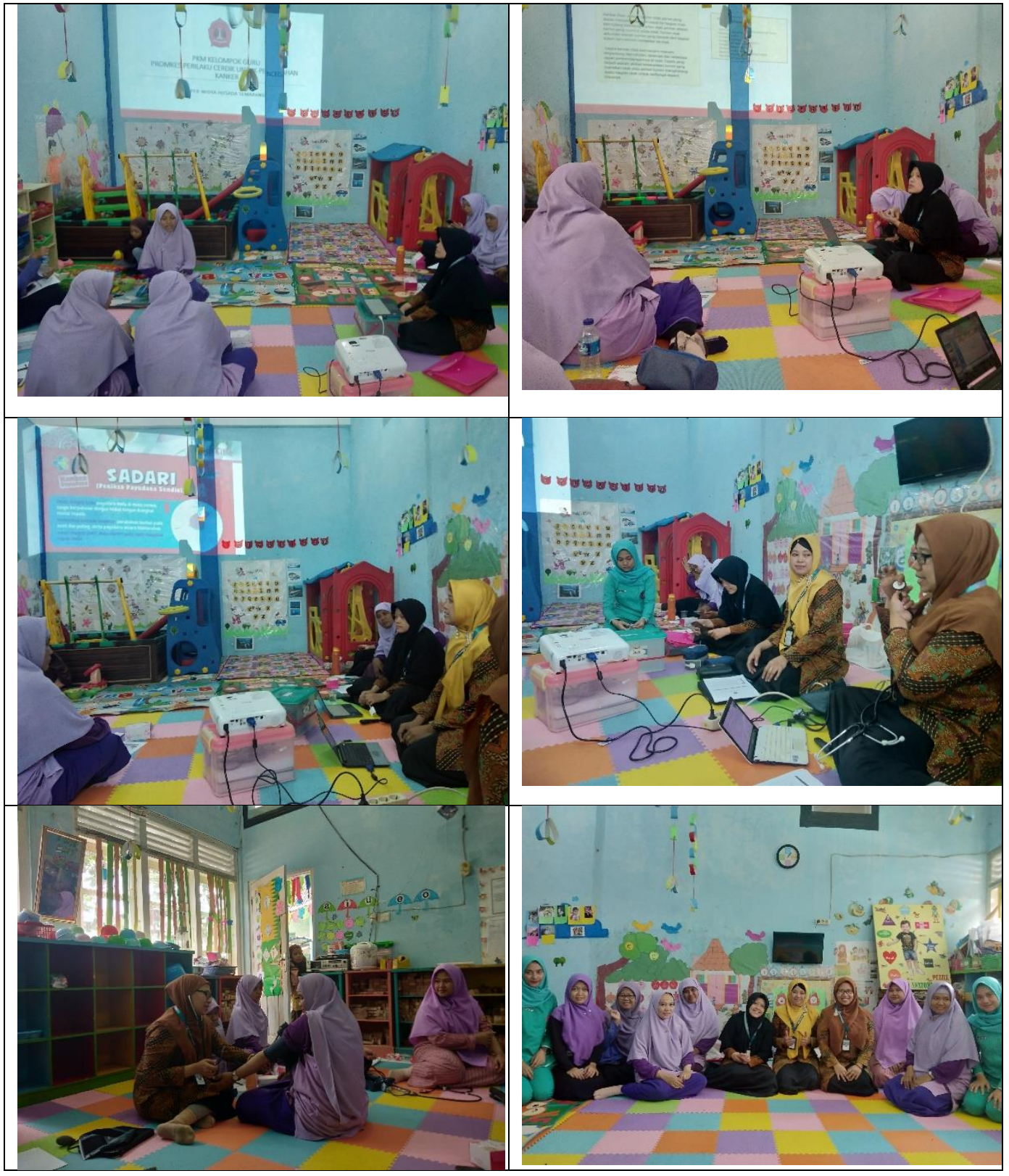

Gambar 2.2 Foto Kegiatan PKM

\section{KESIMPULAN}

Promosi kesehatan perilaku CERDIK ini bertujuan untuk meningkatkan kewaspadaan dan pengetahuan mengenai penyakit kanker, serta menggerakkan masyarakat untuk melakukan upaya pencegahan, deteksi dini dan pengobatan terhadap penyakit kanker. Setelah diberikan promosi kesehatan tentang pencegahan dini kanker, kelompok guru Bina Amal Semarang yang memiliki pengetahuan tinggi sebanyak 12 orang (92\%) dan sebanyak 13 orang (100\%) terampil dalam melakukan pengukuran tekanan darah. 


\section{DAFTAR PUSTAKA}

Arif, Yulinda, \& Fitriyah, N. (2018). Efektivitas Penyuluhan Metode Ceramah Dan Audiovisual Dalam Meningkatkan Pengetahuan Dan Sikap Tentang SADARI di SMKN 5 Surabaya. Jurnal Promkes, 6(2), 116-128. Retrieved from https://ejournal.unair.ac.id/PROMKES/article/view/6439/5917

Kementrian Kesehatan RI. (2015). Panduan Program Nasional Gerakan Pencegahan Dan Deteksi Dini Kanker Kanker Leher Rahim Dan Kanker Payudara, Jakarta: Kementrian Kesehatan RI. http://p2ptm.kemkes.go.id/uploads/2016/10/Panduan-Program-NasionalGerakan-Pencegahan-dan-Deteksi-Dini-Kanker-Kanker-Leher-Rahim-danKanker-Payudara-21-April-2015.pdf

Kementrian Kesehatan RI., (2015). Situasi Penyakit Kanker, Jakarta: Buletin jendela data dan informasi kesehatan. https://pusdatin.kemkes.go.id/article/view/15090700004/situasipenyakit-kanker.html

Machfoedz, dkk, (2005), Metodologi Penelitian Bidang Kesehatan, Keperawatan dan kebidanan, Yogyakarta: Fitrimaya.

Mubarak, W.I. (2012). Ilmu Kesehatan Masyarakat Konsep dan Aplikasi Dalam kebidanan. Jakarta: Salemba Medika.

Notoatmodjo, Soekidjo. (2010). Ilmu Perilaku Kesehatan. Jakarta: Rineka Cipta. Notoatmodjo, Soekidjo. (2010). Promosi Kesehatan Teori dan Aplikasi. Jakarta: Rineka Cipta.

Ulfah A; Lubis N; Mutiara E. (2017). Pengaruh Media Leaflet dan Film terhadap Pengetahuan Tentang Kanker Serviks dan Partisipasi Wanita Dalam Deteksi Dini Kanker Serviks Di Kampung Darek Kecamatan Padangsidempuan Selatan Tahun 2015. Jurnal Ilmiah PANNMED, 11(3), 158-162. Retrieved from http://ojs.polthttp//ojs.poltekkes-

medan.ac.id/pannmed/article/view/90 